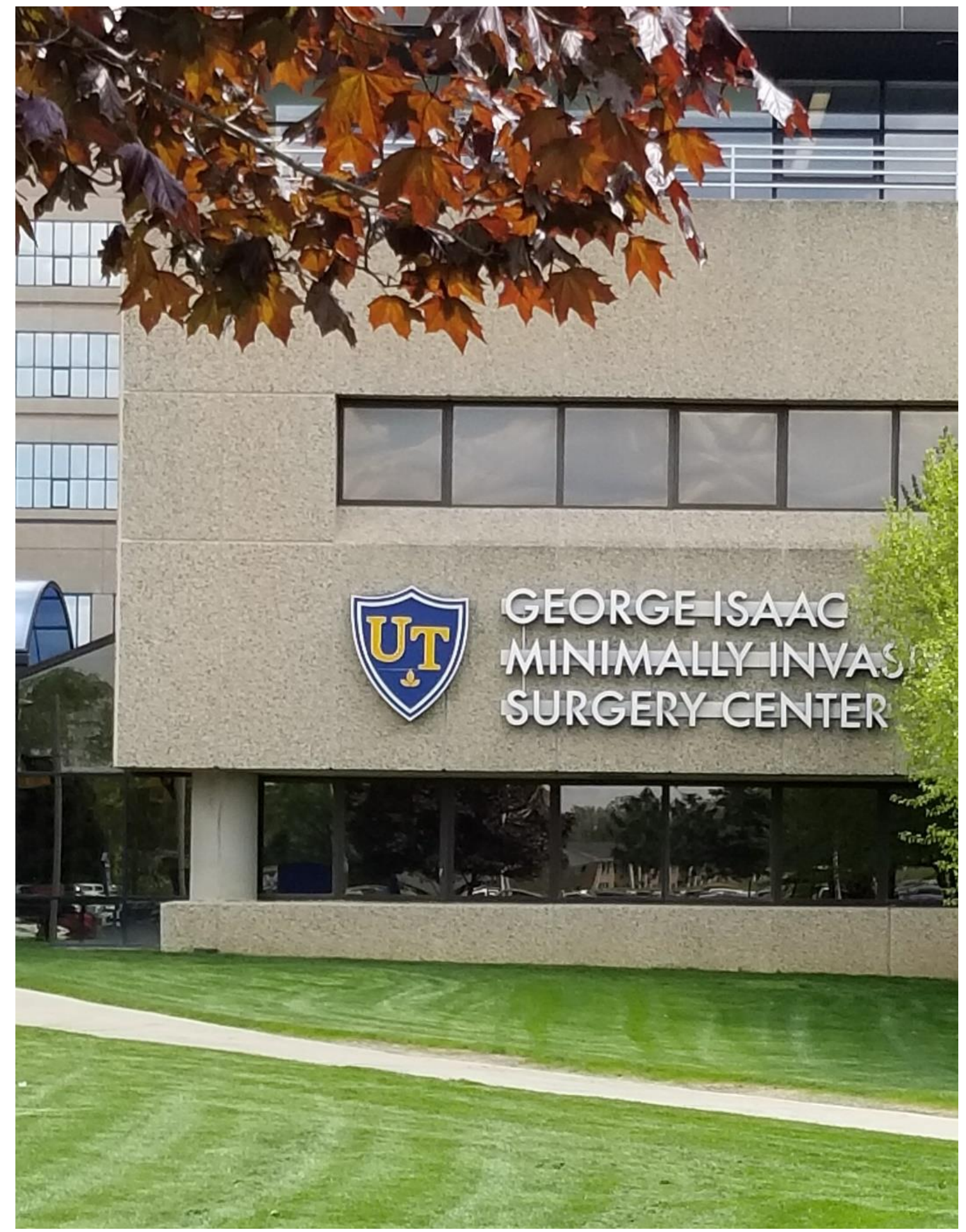




\title{
Role of epigenetics in the pathogenesis and management of type 2 diabetes mellitus
}

\author{
Tajudeen Yahaya ${ }^{a, 1}$ Esther Oladele $^{b}$, Ufuoma Shemishere ${ }^{c}$ and Mohammad Abdulrau'f ${ }^{c}$
}

${ }^{a}$ Department of Biology, Federal University Birnin Kebbi, Nigeria, ${ }^{b}$ Biology Unit, Distance Learning Institute, University of Lagos, Nigeria, and ${ }^{c}$ Department of Biochemistry and Molecular Biology, Federal University Birnin Kebbi, Nigeria

\begin{abstract}
The need to reverse the growing incidence and burden of diabetes mellitus (DM) worldwide has led to more studies on the causes of the disease. Scientists have long suspected genetic and environmental factors in the pathogenesis of type 2 diabetes mellitus (T2DM). However, recent studies suggest that epigenetic changes may cause some cases of the disease. This review highlights the role of epigenetic modifications in the pathogenesis and management of T2DM. Peer-reviewed studies on the subject were retrieved from electronic databases such as PubMed, Google Scholar, SpringerLink, and Scopus. Most of the studies implicated epigenetic modifications in the pathogenesis of some cases of T2DM. DNA methylation, histone modification, and microRNAs mediated pathways are the main mechanisms of epigenetic changes. Certain environmental factors such as diets, microbial and pollutant exposure, and lifestyles, among others, may trigger these mechanisms prior to the onset of T2DM. Epigenetic changes can modify the expressions and functions of some genes involved in insulin biosynthesis and glucose metabolism, leading to hyperglycemia and insulin resistance. Fortunately, epigenetic changes can be reversed by blocking or activating the modulating enzymes. Thus, epigenetic reprogramming can improve some cases of T2DM. Medical practitioners are advised to employ epigenetic therapies for diabetic conditions with epigenetic etiology.
\end{abstract}

| DNA methylation | epigenome | glucose metabolism | hyperglycemia | insulin resistance |

T ype 2 diabetes mellitus (T2DM) is a metabolic disorder often associated with a raised blood glucose level, consequently of the shortage of insulin production by the pancreatic beta cells. Overproduction of glucagon by the pancreatic alpha-cells and insulin resistance in certain tissues, including skeletal muscle, adipose tissue, and the liver may also cause the disorder $(1,2)$. Symptoms of T2DM include abnormal thirst and hunger, repeated urination, weight loss, weakness, poor vision, chronic sores, frequent infections, and dark spots on the skin $(3,4)$. Long - term complications of T2DM develop slowly over time and can devastate health (3). These complications include cardiovascular diseases, diabetic polyneuropathy, renal failure, eye defects, sores, hearing loss, skin problems, and Alzheimer's disease $(3,5)$. T2DM is hereditable, and mutations in at least 100 genes or variants of the genes are linked with the disease $(6,7)$.

Diabetes mellitus (DM) is increasingly occurring worldwide as time passes. For instance, in the U.S., the prevalence of diagnosed DM increased from $0.93 \%$ in 1958 to $7.40 \%$ in 2015 (8). Of the reported DM cases in adults, T2DM accounts for about 90 to $95 \%$ (8). The risk factors of the disease are the consumption of western diets, pollutant and microbe exposures, and physical inactivity $(9,10,11)$. Recently, epigenetic changes are linked with the disease. Scientists are of the opinion that though genetic predispositions could influ- ence the risk of T2DM, most of the candidate genes impair insulin synthesis rather than insulin metabolism $(12,13)$. This suggests that pancreatic islet developmental error might be the main mechanism of T2DM pathogenesis $(12,14)$. The suspect genes do not account for the full transmission of T2DM, meaning that more genetic aspect exists $(12,15)$. The search for this additional genetic factor led to the discovery that modifications of the chemical tags above the genome, often known as epigenetic change, may modulate T2DM (1).

Epigenetic changes are heritable modifications in gene expression and function without affecting the nucleotide sequence (16, 17). Throughout life, epigenetic changes constantly influence chromatin structure and DNA accessibility, activating and deactivating targeted parts of the genome at a specific time $(18,19,20)$. Thus, epigenome helps configure a person's phenotype, including disease pathogenesis (6). This study, therefore, reviewed and established the role of epigenetic changes in the pathogenesis and etiology of T2DM.

\section{Methodology of the Review}

Electronic databases, including: PubMed, Google Scholar, SpringerLink, ResearchGate, Web of Science, and Scopus were searched for relevant information on the topic.

\section{Search Terms}

The following keywords used to retrieve information include: diabetes mellitus, hyperglycemia, insulin, epigenome, epigenetics, and epigenetic modifications. Other search terms used are type 2 diabetes mellitus, epigenetic mechanisms, epigenetic drugs, DNA methylation, histone modification, and insulin resistance.

\section{Criteria for Inclusion of Studies}

Research published in the English language.

Research that focused on the prevalence and pathogenesis of DM. Research that focused on epigenetics of T2DM.

Studies that focused on epidrugs of T2DM.

Studies that were published between 1990 and 2018.

However, the bulk of the information came from studies published

All authors contributed to this paper. ${ }^{1}$ To whom correspondence should be sent: yahaya.tajudeen@fubk.edu.ng

the authors have no conflict to declare. Submitted: 07/28/2019, published: 10/08/2019.

Freely available online through the UTJMS open access option 


\section{Epigenetics in the T2DM}

The articles collected were screened for eligibility according to the PRISMA guidelines $(21,22)$. Criteria such as the study design, affiliation of the authors, and reputation of the journal hosting the articles, were considered in the article selection. Overall, none of the studies included in the review had major flaws to disregard the findings. Several studies agreed that epigenetic changes may initiate or contribute to the pathogenesis and burden of T2DM. DNA methylation, histone modification, and microRNA-mediated pathways are the main mechanisms by which epigenetic changes modify phenotypes, including disease presentations. Prior to epigenetic modification, environmental triggers interact with the genes through certain chemicals on the DNA.

\section{DNA Methylation in T2DM Pathogenesis}

DNA methylation is one of the epigenetic mechanisms in which a methyl group attaches to the DNA, causing a change of gene expression and function. Notable among DNA methylation processes is the covalent addition of a methyl group to the 5-carbon of the cytosine ring, resulting in 5-methylcytosine (5-mC) (23). After methylation, the methyl group protrudes inside the DNA and disrupts the transcriptional processes (24). 5-methylcytosine is present in about $1.5 \%$ of human genomic DNA (24). In somatic cells, 5-mC resides mostly near the $\mathrm{CpG}$ sites, except in the embryonic stem cells, which contain some 5-mC near the non-CpG sites (24). In the germ cells and around the promoters of normal somatic cells, the $\mathrm{CpG}$ sites are un-methylated, allowing gene expression to take place (25).

A class of enzymes known as DNA methyltransferases (DNMTs) mediates the pairing of methyl groups to DNA (26). Three DNMTs, namely DNMT1, DNMT3a, and DNMT3b, are necessary for the initiation and maintenance of DNA methylation processes (25). Two more enzymes, DNMT2 and DNMT3L, are equally important but perform more specialized tasks (25). DNMT1 maintains already methylated DNA, whereas DNMT3a and $3 b$ modulate the creation of new or de novo DNA methylation processes (25). However, in diseased cells, the three enzymes, DNMT1, DNMT3a, and $3 \mathrm{~b}$ interact and cause DNA over-methylation (25). Equally important as DNA methylation in epigenetic modification of organisms is DNA demethylation. The cellular process is the removal of a methyl group from DNA, which is necessary for reprogramming of methylated DNA and reversing disrupted gene expression. Demethylation can occur passively in which a DNMT1 inhibits the methylation of newly synthesized DNA strands during the replication stages (27). It can also occur actively wherein established patterns are demethylated by enzymatic removal of 5-methylcytosine through an enzyme called ten-eleven translocation (TET) (27).

In the last few decades, several studies have implicated DNA epigenome reprogramming in the development and pathogenesis of many chronic diseases, including T2DM. In one study, an examination of pancreatic beta cells of diabetics and non-diabetics showed epigenetic changes in almost 850 genes, over 100 of which had disrupted expression (16). In another study, 17 T2DM predisposing genes, including TCF7L2, THADA, KCNQ1, FTO, and IRSI, showed varying degrees of methylation in the pancreatic islets of individuals with T2DM (1). Increased expression and decreased methylation of CDKN1A and PDE7B gene was also impaired in glucose-stimulated insulin synthesis in the individuals with diabetes (1). A gene called EXOC3L2, which is important in insulin transport, was also repressed and over-methylated in the pancreatic islets
Studies have established that small changes in gene expression over time may have an enormous effect on DM (28). The epigenome depends on the cell or tissue type, and so does epigenetic modification processes leading to disease pathogenesis. In pancreatic islets, the PPARGC1A gene provides instruction for the synthesis of a transcriptional co-activator that regulates mitochondrial oxidative metabolism (29). The expression of this gene enhances glucosestimulated insulin release from human islet cells (30). However, in the pancreatic islets of individuals with T2DM, the PPARGC1A promoter is over-methylated, which repressed the PPARGC1A gene compared with non-diabetic (31). Another gene called UNC13B, on chromosome 9 and embedded in kidney cortical epithelial cells, has also been reported to be over-methylated in diabetic patients (32).

Since obesity predisposes T2DM, methylation in adipose tissue would ideally have a vital role to play in the disease's pathogenesis (33). Indeed, studies have proven the involvement of adipose tissue methylation in the onset of T2DM. For example, DNA methylation in the promoter of the ADRB3 gene in visceral adipose tissue causes abnormal waist-to-hip ratio and blood pressure in obese men (34). In addition, the PPARGC1A gene in subcutaneous adipose tissue showed altered DNA methylation after a high-fat diet (35). This finding again highlights the involvement of the PPARGC1A in epigenetic modulation of metabolic processes in several tissues, including adipose and skeletal muscle [36] and pancreatic islets (30). In a study, the visceral adipose tissue of the obese showed 3, 258 methylated genes, indicating the role of epigenetic changes in obesity pathogenesis (37). A detailed genome-wide DNA methylation analysis of adipose tissue has also revealed evidence of over-methylation of tissue-specific molecules that regulate gene expression and susceptibility to metabolic disorders (38). Adipose tissues particularly showed altered DNA methylation in an enhancer molecule upstream of ADCY3 (39).

\section{Histone Modification in T2DM Pathogenesis}

Histones are the protein building blocks of chromatin - a mass of genetic material composed of DNA and protein - and form the backbones of the helical structure of the DNA. Modification of histones after being translated into protein can program the structural arrangement of chromatin (40). The resulting structure determines the transcriptional status of the associated DNA (40). Noncondensed chromatin is active and results in DNA transcription, whereas condensed chromatin (heterochromatin) is inactive and incapable of transcription (40).

Several mechanisms, namely acetylation, methylation, phosphorylation, and ubiquitylation, can modify histones; however, acetylation and methylation are the most frequently occurring mechanisms (41). Acetylation adds an acetyl group to the amino acid lysine in the histone, while methylation involves the addition of a methyl group (42). Acetylation typically occurs in non-condensed chromatin, while deacetylation often occurs in condensed chromatin (40). Histone methylation can occur in both forms of chromatin (40). For instance, methylation of a particular lysine (K9) on a specific histone $(\mathrm{H} 3)$ represents inactive chromatin, while methylation of a different lysine (K4) on the same histone $(\mathrm{H} 3)$ reveals active chromatin (40). Histone modification involves several enzymes, notably the histone deacetyltransferases (HDACs), which deacetylates amino-terminal lysine residues on histone ends (41). Thus, allowing the lysine residues to bind more tightly to the DNA (41). The genes in the more tightly bound regions become repressed because of the inaccessibility of the transcription factors into the promoters of the genes (41). 
Studies have reported histone modifications in diabetic patients. For instance, histone acetyltransferases (HATs) and HDACs are linked to the altered expression of some genes in diabetics (43). One example is the SIRT family of HDACs; specifically, SIRT1 regulates several factors involved in metabolism, adipogenesis, and insulin synthesis (43). In an experiment, a high glucose treatment of monocytes in-vitro increased the production of the HATs CREB-binding protein $(\mathrm{CPB})$ and P300/CBP-associated factor (PCAF) (43). This resulted in over-acetylation of histone lysine at the cyclooxygenase2 (COX-2) and TNF-inflammatory gene promoters, causing overexpression of the genes (43). Similar over-acetylation of histone lysine at these gene promoters occurs in patients with T2DM compared with control (43).

\section{MicroRNAs (miRNA) in T2DM Pathogenesis}

Micro RNAs (miRNAs) are single-stranded transcribed RNAs between 19 and 25 nucleotide chains (44). They are a class of small, noncoding RNA molecules that modulate gene expression at the translational level by disrupting the 3' un-translated region of messenger RNAs (44). MicroRNAs interact with transcriptional and epigenetic modulators for the maintenance of lineage-specific gene expression (45). Specifically, MicroRNAs regulate gene expression at the post-transcriptional level by preventing the translation of target messenger RNA (46). However, in diseased individuals, the expression of microRNAs often changes, resulting in altered expression, mainly over-expression of the target genes (46). MicroRNAs are important in the maintenance of several biological processes, such as cell cycle control, cell differentiation, and apoptosis, among others (44). Studies have confirmed functional impairment of miRNAs in several pathologies, including cancer, respiratory diseases, heart diseases, and DM [44].

An experiment performed by Kameswaran et al. (47) investigated the involvement of microRNAs in the pathogenesis of T2DM. The scientists sequenced the microRNAs of islets obtained from individuals with T2DM and non-diabetics and found a mass of altered microRNAs on chromosome 14q32 (47). The locus was strongly and specifically expressed in beta-cells of non-diabetics but repressed in the islets of individuals with T2DM (47). The downregulation of this locus strongly correlates with the hyper-methylation of its promoter (48). In another study, Martinez et al. (49) showed that miR-375 is among the miRNAs embedded in the pancreatic islets, and its altered expression may lead to T2DM. Over-expression of this miRNA reduces glucose-induced insulin release, while its inhibition promotes insulin secretion (49). Studies have observed a similar relationship between miRNA-192 and miRNA-9 hypermethylation and insulin secretion, showing that miRNAs may play a role in the onset of DM (49).

\section{Triggers of Epigenetic Changes in T2DM}

There are some environmental factors, which may trigger epigenetic changes prior to the onset of T2DM. These triggers induce epigenetic changes by adding or removing epigenetic tags from the DNA, histones, and miRNAs. These tags are chemicals or molecules such as methyl and acetyl groups capable of changing gene expression.

\section{Aging}

Mitochondrial metabolic activities in skeletal muscle decline with age and degenerate faster in elderly with insulin resistance and T2DM (50). Genetic and environmental factors were previously considered the only links between mitochondrial decline and aging (51). However, recent studies show epigenetic patterns also change with age, affecting the expression of some genes involved in glucose metabolism in the respiratory chain (51). In particular, the COX7A1 gene is down-regulated in the skeletal muscle of elderly individuals with T2DM (51). In a study, over-methylation and repression of mRNA occurred in the promoter region of COX7A1 gene in the skeletal muscle of elderly compared with middle-aged (51). These findings showed that aging could influence DNA methylation, gene expression, and metabolic activities. Decreased gene expression with aging, resulting in reduced metabolic activities, was also observed in the enhancer of other insulin-promoting genes, such as NDUFB6 (52).

Aging may worsen insulin resistance in the liver, resulting in T2DM (53). Glucokinase, an enzyme that stimulates the liver to absorb glucose, is under-produced in the liver of diabetics (53). In an experiment involving old and young rats, the livers of aged rats showed decreased glucokinase expression in response to overmethylation of the glucokinase promoter (54). Culturing of the hepatocytes of the aged rats and the demethylation of the DNA resulted in a marked rise in glucokinase expression (54). This shows an epigenetic modification of the hepatic glucokinase promoter may represent a pathway for T2DM pathogenesis.

\section{Physical Inactivity/Sedentary Life}

Physical inactivity can influence the epigenome negatively, affecting several generations (55). Human physical activity has reduced drastically since the invention of technologies in the 19th century, resulting in the increasing overweight of people worldwide. Increasing physical inactivity has contributed immensely to the growing global burden of obesity, a risk factor of T2DM $(56,57$, 58). Some mechanisms through which inactivity mediates diseases include mitochondrial dysfunction, changes in the composition of muscles, and insulin resistance, among others (59). Physical inactivity can also program the health of the offspring across several generations $(60,61,62)$. Increased physical activity can help prevent, lessen, or reverse several health conditions, including T2DM $(60,61)$. Increased exercise was reported in the methylation of certain genes that predispose to some chronic diseases (63). For example, exercise causes demethylation of certain genes that promote the secretion of pro-inflammatory cytokines, reducing the risk of chronic diseases, including DM (63).

Several studies report genome-wide changes in DNA methylation in response to exercise. In one study, gene expression in muscle tissues following an exercise changed the efficiency of glucose metabolism by the muscle (63). Some studies which sought to know the amount of exercise needed to accomplish changes in DNA methylation of muscles reported it depended on exercise intensity (63). In obese individuals, exercise can modify the absorption of fats into the body. In a genome-wide adipose tissue methylation study of sedentary men, changes in about $18,000 \mathrm{CpG}$ sites (encompassing 7,663 genes) occurred in the individuals after 6-month exercise (64).

The methylation occurred in obesity and T2DM predisposing genes such as TCF7L2 and KCNQ1, meaning that the exercise silenced these genes (64). In a study of skeletal muscles, 2,817 genes were methylated after 6-month exercise, but unlike the adipose tissue, most of the genes showed decreased levels of DNA methylation (65). Over-methylation of the skeletal muscle raised the expression of pro-inflammatory cytokines, which silenced some insulinpromoting genes (66). Exercise induces the expression of several genes, such as GLUT4 that regulate glucose uptake in skeletal muscle (67). 
Exercise may also induce histone modifications. When a human is at rest, MEF2 interacts with HDAC5 in the nucleus, leading to deacetylation of the GLUT4 gene at the histone end (68). This creates condensed chromatin, repressing GLUT4 expression (68). During exercise, AMP-activated protein kinase phosphorylates HDAC5, splits from MEF2, and migrates to the cytosol from the nucleus (69). MEF2 may then interact with PPARGC1A and HATs in the nucleus (68). This leads to acetylation of the GLUT4 gene histone, which enhances the expression and transcriptional activity of the gene (69). $\mathrm{Ca} /$ calmodulin-dependent protein kinase $(\mathrm{CaMK})$ may also modulate the MEF2 activity through histone acetylation after exercising for a short duration $(70,71)$.

\section{Nutrition Choices}

The epigenetic effects of diets are the most studied and understood of all the environmental triggers of epigenetic changes. Nutrients undergo a series of metabolic reactions to become molecules the body can use. One of these reactions creates methyl groups (72). Nutrients that induce methyl-making include folic acid, B vitamins, some drugs, etc. (73). Diets rich in these compounds can alter gene expression, especially during early development, when the epigenome is young (74). The diet of a mother during pregnancy and the baby's diet can program the baby's epigenome for life (72).

Experiments in mice have demonstrated the role of a mother's diet in shaping the epigenome of offspring. For instance, when a mammalian gene called agouti was completely un-methylated in mouse, its skin turned yellow and became obese, predisposing it to DM (72). When the agouti gene was methylated like normal mice, the skin color turned brown and reduced its disease risk (72). Fat yellow mice and skinny brown mice are genetically identical, but modification exists in the epigenome of the fat yellow mice (72). When the yellow mice ate a methyl-rich diet, most of their newborns were brown and were healthy throughout life. These results show that the intrauterine environment can influence adult health (72).

The diet of a dad can also influence his child's epigenome. Records showed that the amount of food consumed at ages 9 to 12 by some Swedish paternal grandfathers affected the lifespan of their grandchildren (75). Shortage of food relates to the increased lifespan of the grandchildren, while abundant food, mediated by either DM or heart disease, shortens their lifespan (75). Epigenetic mechanisms could have programmed the nutritional information of the grandfathers and transmitted it to subsequent generations (75).

Energy-dense diets can also induce profound epigenetic modifications. High-fat diets can influence the gut microbiota to increase body accumulation of fat (76) and program the epigenome of a developing embryo. This implies that frequent consumption of fatladen diets such as western diets may cause multi-generational programming of obesity (56). A paternal high-fat diet can cause transgenerational metabolic traits such as weight and fat gain, glucose intolerance, among others (77). These conditions are caused by abnormal methylation of certain regions and genes in the sperm cells, such as adiponectin, leptin, IGF2, MEG3, SGCE/PEG10, MEG3IG and H19 DMRs $(78,79)$. Maternal high-fat diets also relate to altered gene expression, DNA methylation, and obesity risk (80). In a rat experiment, maternal high-fat diets increased obesity risk in the high-fat-fed daughters, increasing their body weight, fat accumulation, and serum levels of leptin as adults (80).

Apart from high-fat diets, adverse intrauterine environments such as inflammation and endoplasmic reticulum stress may epi- genetically program for childhood obesity involving several genes. The programming may even switch the preference of a child to energy-dense foods, leading to over-nutrition and obesity $(81,82$, 83). Childhood reduced DNA methylation of LINE1 and increased methylation of some genes, including CASP10, CDKN1C, EPHA1, HLADOB3, IRF, etc., occurred in individuals predisposed to childhood obesity $(84,85)$. Over-nutrition during childhood increases the risk of developing obesity in childhood through to adulthood (86).

The fruits and vegetables in a human's diet may also influence his/her epigenome with heritable effects. Eating too few fruits and vegetables may cause low serum levels of methyl-donating minerals and vitamins, which are important regulators of the epigenome during intrauterine life (56). For example, folate, choline, and betaine metabolism generate $\mathrm{S}$-adenosyl methionine, which can influence DNA and histone methylation by supplying methyl groups to DNA and histone methyltransferases (87). A deficiency of these compounds may lead to widespread altered DNA methylation at 57 $\mathrm{CpG}$ loci in the offspring (88). About $4 \%$ of the $1,400 \mathrm{CpG}$ islands examined in a study had altered methylation status, $88 \%$ of which were hypo-methylated relative to controls (88).

Whole-grains (unrefined grains) reduce the risk of T2DM (89) and metabolic syndrome (90). However, in the bid to make wholegrains more tasteful, technological advancement has introduced a lot of refined grains into the market with less fiber and nutritional content. Refined grains are energy dense and have a high glycemic index, thus causing higher glycemic and insulin responses following consumption, with increased risks of developing T2DM (91). Rice, in particular, is the staple food of half of the world population and is increasingly being consumed worldwide (92). Some scientists suspected ancestral epigenetic programming towards a preference for rice consumption. However, refined white rice with characteristics of high glycemic index and low fiber content contributes to the global explosion of T2DM. In a study, feeding of white rice to female rats for eight weeks prior to pregnancy and throughout pregnancy and lactation showed significant differences in metabolic indices compared with brown rice feeding (93). These indices relate to insulin resistance and insulin signaling genes in hepatic, adipose, and muscle cells (93).

Starvation around conception time and early gestation is another factor that can influence the epigenome of humans. Starvation during fetal development causes either hypo-methylation or hypermethylation of many genes, including the insulin receptor (INSR) gene, which is important in insulin synthesis and metabolism during adulthood. The placenta modulates the exchange of molecules, including nutrients between the mother and fetus; thus, this function makes the placenta the target of epigenetic changes during starvation (94). Starvation can modify placenta epigenome through gene methylation or modification of miRNAs associated with genes necessary for fetal development, nutrient transfer, and disease prevention (94). In an experiment, mice short of food during pregnancy produced first-generation diabetic offspring and predisposed second-generation offspring (95). Normally, the body removes most of the methyl groups upon the formation of an embryo except for methyl groups on a few genes (95). Nutrient starvation in the mother may also alter normal methylation patterns in the sperm cells (95). In an experiment, scientists observed reduced methylation of 111 genomic regions in the offspring of starved mothers compared with the controls. In the study, over-methylated 55 regions also occurred in the DNA of the offspring of the starved mothers (95). In another study, children born to starved mothers showed differential methylation of IGF2 and other T2DM-related genes, which further proved epigenetics as a mechanism linking prenatal nutrition and 
adult-onset of T2DM (96).

\section{Lifestyle and Chemical Exposure}

Chemical exposure influences the epigenetic programming of some diseases. For instance, smoking during pregnancy directly affects the fetus, causing health conditions such as low birth weight and increased risk for several diseases, such as T2DM (97). Maternal cigarette smoking during pregnancy related with altered DNA methylation and disrupted microRNA expression (98). These conditions were thought to result from some toxic chemicals in tobacco, but some evidence points to the involvement of epigenetic alterations (98). Thus, besides the direct effects of tobacco smoking, epigenetic alterations induced by its chemicals can modulate some smoking-related risks of developing many diseases, including T2DM (98). Some of these epigenetic changes are heritable; thus smokers may produce offspring with tobacco-smoke related problems lasting long until adulthood (56).

In a study, tobacco smoke induced long-term lymphocyte DNA methylation changes in several $\mathrm{CpG}$ sites and genes, increasing the risks of some diseases, including T2DM (99). These conditions persisted for at least three decades, indicative of multi-generational consequences of smoking (99). Findings suggest that there are a variety of placental dysfunctions linked to prenatal exposure to cigarette smoke, including alterations to the development and function of the placenta (100). In a research by Wilhelm-Benartzi et al. (101), differential methylation of repetitive molecules on placenta DNA relates to birth weight and maternal smoking during pregnancy (101). In another study, men who smoked around 11 years of age showed massive epigenetic changes in the genes imprinted on the Y chromosome (102). These men produced overweight male offspring by age 9 . This means the sons of men who smoke before puberty will be at higher risk for obesity and other health problems well into adulthood (102). Methylation of germline or placenta may transmit these effects across many generations $(96,98)$. Thus, widespread smoking and inhalation of second-hand smoke may affect smokers and nonsmokers across many generations through epigenetic reprogramming (103). This underscores the involvement of tobacco in the global upsurge of several chronic diseases beginning from the 19th century (56). Similarly, alcohol addiction can cause or worsen several health problems. If consumed in excess during pregnancy, alcohol can cause fetal alcohol syndrome, such as low birth weight, impaired cognitive and neuropsychological functions (104). Alcohol interferes with folate metabolism and reduces overall methylation levels in mice exposed to alcohol in utero (105). Alcohol can induce extensive DNA methylation of the germline of a man and transmit the epigenetic changes to his offspring via conception. Alcohol-induced placental epigenetic changes are also heritable via the female germline (104). Alcohol addiction by men can increase the chances of alcoholism in male offspring (106). Thus, children exposed to alcohol prenatally already have epigenetically predetermined increased risks of some diseases, including T2DM, subsequent consumption of alcohol only worsens the epigenetic programming (56).

Pollutant exposure is another burden with serious effects on the health of humans. Evidence abounds that prenatal exposure to some toxic pollutants can increase the risk of multi-generational transmission of some diseases (56). For example, maternal and paternal exposure to dichlorodiphenytrichloroethane (DDT) increases the obesity risks of future generations through epigenetic alterations in obesity-related genes in both male and female germ lines (107). Some other chemicals, including bisphenol-A (BPA), bis (2-ethylhexyl) phthalate (DEHP), and dibutyl phthalate (DBP) can also increase the risk of epigenetic transgenerational inheritance of adult metabolic diseases (108). Embryonic exposure to BPA gen- erates metabolic disturbances later in life, such as obesity and DM (108). BPA and other endocrine disruptors can alter fat tissue development and growth by disrupting the production of functional adipocytes and their differentiation (108). Several studies showed that BPA-induced multi-generational effects, such as obesity may involve epigenetic mechanisms (108). Other pollutants, including pesticides, agrochemicals, among others, can also induce transgenerational extensive epigenetic changes with a consequent increase in the risk of adult diseases (109).

\section{Epigenetic Therapies for T2DM}

Several studies showed that epigenetic changes are reversible, so its mechanism can be used to predict, prevent, reverse, or lessen many diseases induced by epigenetic changes, including T2DM. In fact, many drugs, tagged epigenetic drugs (or epidrugs), are in use or under clinical evaluations for T2DM management. Epidrugs work by inhibiting or activating the enzymes that mediate epigenetic changes.

\section{DNA Methylation Inhibiting Drugs}

Many diseases caused by over-methylation of certain genes can be reversed by blocking or inhibiting the methylating enzymes. Several DNA methylation inhibitors, mostly nucleoside-like compounds, have been formulated to manage some diseases (110). One of the epidrugs, known as 5-Azacytidine has cytotoxic effects on cancer cells (110). The most common T2DM drug known as metformin works by decreasing DNA methylation of metformin transporter genes in the human liver (111). Hyper-methylation of metformin transporter genes causes high blood sugar and obesity (111), which are hallmarks of T2DM. The discovery of another drug named procainamide has further added to the growing number of epidrugs with therapeutic effects on T2DM (112). Procainamide boosts insulin secretion through DNA demethylation (112) of certain genes in the beta cells and, if taken with an oral hypoglycemic agent such as metformin, its effects will increase (112).

\section{Histone Acetyltransferase Inhibitors (HATIs)}

Many HATIs such as garcinol, extracted from garcinia fruit rinds have therapeutic effects on T2DM (113). Garcinol lessens inflammation of retinal Muller cells in a high concentration of glucose, which indicates that it can prevent diabetic retinopathy (114). Anacardic acid is another epidrug obtained from cashew nuts and enhances glucose assimilation by $\mathrm{C} 2 \mathrm{C} 12$ muscle cells through epigenetic changes (115). In animal models, curcumin from turmeric showed hypoglycemic and hypolipidemic effects (116). Curcumin can also elevate postprandial serum insulin concentrations while maintaining blood glucose levels in normal individuals (117).

\section{Histone Deacetylase Inhibitors (HDAIs)}

Histone deacetylases (HDACs) are enzymes that detach acetyl group from lysine residues on the histones, disrupting the epigenome and causing diseases (118), including T2DM. However, some substances called histone deacetylase inhibitors (HDACIs) can inhibit these enzymes, preventing or reversing deacetylation and the associated diseases (118). HDACIs are small epigenetically active molecules (119) and the first major one discovered was n-butyrate, which causes hyperacetylation of histones in the cells (120). Trichostatin A (TSA) and trapoxin A (TPX) are also HDACIs, which are epidrugs capable of inhibiting HDAC activity $(121,122)$. Some HDACIs such as TSA and depsipeptide FK228 are natural products from certain microbes (118). Some others, such as suberoylanilide hydroxamic acid (SAHA) are synthesized using the structural information of some naturally occurring HDACIs 
(118). In addition, some dietary substances such as vegetables, fruits, whole-grains, among others, have HDAC inhibiting properties comparable to pharmacological HDACIs without side-effects (118).

In DM management, some HDACIs improve diabetic conditions by reversing the cytokine-induced damage of pancreatic beta cells $(123,124,125)$. Other HDACIs promote insulin secretion and performance and increase beta cell mass $(126,127,128)$. However, as a precautionary measure, high doses of HDACIs must be avoided as they are cytotoxic (125).

\section{MicroRNA (miRNA) Inhibitors}

The maintenance of the normal functioning of the body is in part regulated by certain miRNAs, which are often disrupted in diseased individuals. Scientists have demonstrated that by restoring affected miRNAs to the normal state, its associated diseases can be prevented or reversed. MicroRNAs restoration can be achieved either by normalizing the expression of repressed miRNAs using miRNA mimics or disrupting the activity of overexpressed miRNAs using miRNA inhibitors (129). MicroRNA inhibitors are antisense oligonucleotides (129) designed based on the molecular properties of the target miRNA to bind to it and activate the target gene. Some proven miRNA inhibitors include locked nucleic acid (LNA) antimiRs, antagomirs, and morpholinos $(130,131)$. LNA anti-miRs are exceptionally efficient, less toxic, and great therapeutic potential (132). LNA anti-miR-122 reduces plasma cholesterol with no sign of toxicity in mice (133). The antisense oligonucleotide 2'-Omethyl-miR-375 normalizes insulin secretion in-vitro by boosting the expression of 3'-phosphoinositide-dependent protein kinase-1 (PDK-1) (122). Some epidrugs like Byetta, Victoza, Trulicity, Januvia, Onglyza, and Tradjenta modify over-expressed miR-204 in the beta cells of diabetics (134). This activates glucagon-like peptide 1 receptor, or GLP1R, assisting the beta cell to synthesize more insulin (134).

\section{Conclusion}

T2DM is a multifactorial disorder, and so its development in an individual is multifaceted. However, several studies reviewed showed that epigenetic changes, starting from intrauterine life to adulthood, may play a critical role in the pathogenesis of some cases of the disease. Some environmental factors such as diet choice, pollutant, and microbial exposure, and lifestyles may trigger epigenetic

1. Dayeh T, Petr V, Sofia S, et al. (2014). Genome-Wide DNA Methylation Analysis of Human Pancreatic Islets from Type 2 Diabetic and Non-Diabetic Donors Identifies Candidate Genes That Influence Insulin Secretion. PLOS/Genetics 10: 1-20. DOI: 10.1371/journal.pgen.1004160.

2. Alessio D. (2011). The role of dysregulated glucagon secretion in type 2 diabetes. Diabetes Obes Metab 1:126-32. Doi: 10.1111/j.1463-1326.2011.01449.x.

3. Mayo Clinic. Type 2 Diabetes Mellitus Overview. Available Online at https://www.mayoclinic.org/diseases-conditions/type-2-diabetes/symptomscauses/syc-20351193. (Accessed December 16 2018).

4. Ramachandran A. (2014). Know the signs and symptoms of diabetes. Indian $J$ Med Res 140 (5):579-81.

5. Papatheodorou K, Papanas N, Banach M, Papazoglou D, Edmonds M. (2016). Complications of Diabetes. J Diabetes Res Article ID 6989453. Doi: 10.1155/2016/6989453

6. What is Epigenetics? Type 2 Diabetes Mellitus and Epigenetics. Available Online At https://www.whatisepigenetics.com/type-2-diabetes-mellitusand-epigenetics/. (Accessed December 17 2018).

7. Ali O. (2013). Genetics of type 2 diabetes. World J Diabetes 4 (4):114-23. Doi: 10.4239/wjd.v4.i4.114

8. Center for Disease Control and Prevention. Data and Statistics: What's New in Diabetes? Available Online at https://www.cdc.gov/diabetes/data/ (Accessed December 18 2018) changes in individuals prior to the onset of T2DM. Fortunately, epigenetic changes are reversible, so health care providers can use epigenetic modifications to reverse or treat DM induced by epigenetic changes. Several epigenetic drugs are in use; however, most of the drugs need improvement to achieve the desired results.

Table 1. Reference numbers by subjects.

Reference number

\section{Etiology}

DNA Methylation and Demethylation

Histone modification

$1,16,23-39$

$41,42,43$

Functional impairment of miRNA

$44,45,46,47,48,49$

Triggers

Aging

$51-54$

Physical Inactivity

and Sedentary Lifestyles

55-69

Life styles and Chemical exposure

96-109

\section{Therapies}

DNA Methylation inhibitors

Histone Acetyltransferase Inhibitors (HATIs)

Histone Deacetylase Inhibitors (HDAIs)

$110,111,112$

113- 117

$118-127$

MicroRNA (miRNA) Inhibitors

$122,129-134$

\section{Conflict of interest}

The authors declare no conflict of interest.

\section{Authors' contributions}

TY and EO wrote the manuscript, US and MA revised the manuscript. All authors have read and approved the final document.

9. Chen L, Magliano D J, Zimmet P Z. (2012). The worldwide epidemiology of type 2 diabetes mellitus\{present and future perspectives. Nat Rev Endocrinol 8: 228\{ 236. DOI: 10.1038/nrendo.2011.183.

10. Yahiya T, Obaroh $O \mathrm{I}$, Oladele, O E. (2017). The Roles of Microorganisms in the Pathogenesis and Prevalence of Diabetes: A Review.AJDM 25: 13-15. DOI: 10.4314/jasem.v21i1.1.

11. Yahaya T, Umar AK., Zafira Z1. (2018). The Possible Link Between Mineral Deficiencies and Diabetes Mellitus: A Review. NRJCS 4: 1- 13.

12. McCarthy M. (2010). Genomics, Type 2 Diabetes, and Obesity. NEJM 363: 2339\{2350. DOI: DOI: 10.1056/NEJMra0906948

13. Rolin B, Larsen MO, Gotfredsen CF, et al. (2002). The long-acting GLP-1 derivative NN2211 ameliorates glycemia and increases beta-cell mass in diabetic mice. Am J Physiol Endocrinol Metab 283:E745 - 52

14. Gilbert RE, Liu G. (2012). The missing link to understanding-cell dysfunction in the pathogenesis of type 2 diabetes. Epigenetics 7 (8): 841-852 https://doi.org/10.4161/epi.21238

15. Slomko H, Heo HJ, Einstein FH. (2012). Minireview: Epigenetics of obesity and diabetes in humans. Endocrinology 153: 1025-1030. DOI:10.1210/en.2011-1759

16. Ling C, Groop L. (2009). Epigenetics: a molecular link between environmental factors and type 2 diabetes. Diabetes 58: 2718-2725. DOI: 10.2337/db09-1003.

17. Handy DE, Castro R, Loscalzo J. (2011). Epigenetic modifications: basic mechanisms and role in cardiovascular disease. Circulation 123 (19): 2145-56. Doi: 10.1161/CIRCULATIONAHA.110.956839 
18. 18. Bird A. (2007). Perceptions of epigenetics. Nature 447:396-398. DOI: 10.1038/nature05913

19. 19. Kanherkar RR, Bhatia-Dey N, Csoka AB. (2014). Epigenetics across the human lifespan. Front Cell Dev Biol 2: 49. Doi:10.3389/fcell.2014.00049

20. Matro A, Caputo J B, Vagula C M. (2014). Cognitive impairment and dementia in Type 2 diabetes mellitus. US Pharm 39:33-37.

21. Moher D, Liberati A, Tetzlaff $J$, et al. (2009). Preferred reporting items for systematic reviews and meta-analyses: The PRISMA statement. PLoS Med 6 (7): e1000097. doi:10.1371/journal. pmed.1000097

22. Spencer L, Ritchie J, Lewis J, Dillon L. (2003). National center for social reach. Quality in Qualitative Evaluation: A framework for assessing research evidence: A Quality Framework. London: Cabinet office, Government Chief Social Researcher's Officer/

23. Nilsson E, Ling C. (2017). DNA methylation links genetics, fetal environment, and an unhealthy lifestyle to the development of type 2 diabetes. Clin Epigenetics 9 : 105-112 Doi:10.1186/s13148-017-0399-2

24. Lister R, Pelizzola M, Robert H D, et al. (2009). Human DNA methylomes at base resolution show widespread epigenomic differences. Nature 462:315-322. DOI:10.1038/nature08514

25. What is Epigenetic. DNA Methylation. Available at https://www.whatisepigenetics.com/dna-methylation/fn-23-1 (Accessed December 18 2018)

26. Moore LD, Le T, Fan G. (2012). DNA methylation and its basic function. Neuropsychopharmacology 38 (1):23-38. Doi: 10.1038/npp.2012.112

27. Chen Z-X, Riggs AD. (2011). DNA Methylation and Demethylation in Mammals. $J$ Biol Chem 286:18347-18353. Doi: 10.1074/jbc.R110.205286

28. Toperoff G, Aran D, Kark J D, et al. (2012). Genome wide survey reveals predisposing diabetes type 2-related DNA methylation variation in human peripheral blood. Hum Mol Genet, 21:371-383. DOI:10.1093/hmg/ddr472

29. Ling C, Poulsen P, Carlsson E, et al. (2004). Multiple environmental and genetic factors influence skeletal muscle PGC-1 and PGC- 1 gene expression in twins. $J$ Clin Invest 114:1518-26. DOI: 10.1172/JCI200421889.

30. Ling C, Del Guerra S, Lupi R, et al. (2008). Epigenetic regulation of PPARGC1A in human type 2 diabetic islets and effect on insulin secretion. Diabetologia 51: 615-622. DOI: 10.1007/s00125-007-0916-5

31. Alibegovic AC, Sonne MP, Hjbjerre L, et al. (2010). Insulin resistance induced by physical inactivity is associated with multiple transcriptional changed in skeletal muscle in young men. Am J Physiol Endocrinol Metab 299: 572-563. DOI: 10.1152/ajpendo.00590.2009.

32. GeneCards. UNC13B Gene (Protein Coding). Available Online at https://www.genecards.org/cgi-bin/carddisp.pl?gene=unc13B. (Accessed Jan 4 2019)

33. Ronti T, Lupattelli G, Mannarino E. (2006). The endocrine function of adipose tissue: An update. Clin Endocrinol (Oxf) 64:355\{65. DOI: 10.1111/j.13652265.2006.02474.x

34. Guay SP, Brisson D, Lamarche B, et al. (2014). ADRB3 gene promoter DNA methylation in blood and visceral adipose tissue is associated with metabolic disturbances in men, Epigenomics 6:33\{43. DOI: 10.2217/epi.13.82.

35. Gillberg L, Jacobsen SC,nn T, Brns C, Vaag A. (2014). PPARGC1A DNA methylation in subcutaneous adipose tissue in low birth weight subjectsimpact of 5 days of higfat overfeeding, Metabolism 63:263\{71. DOI: 10.1016/j.metabol.2013.10.003

36. Gillberg L, Jacobsen S, Ribel-Madsen R, et al. (2013). Does DNA methylation of PPARGC1A influence insulin action in first degree relatives of patients with type 2 diabetes? PLOS One 8: e58384. DOI: 10.1371/journal.pone.0058384.

37. Guénard $F$, Tchernof $A$, Deshaies $Y$, et al. (2014). Differential methylation in visceral adipose tissue of obese men discordant for metabolic disturbances. Physiol Genomics 46:216\{22. DOI: 10.1152/physiolgenomics.00160.2013.

38. Grundberg E, Meduri E, Sandling JK, et al. (2013). Global analysis of DNA methylation variation in adipose tissue from twins reveals links to diseaseassociated variants in distal regulatory elements. Am J Hum Genet 93:876\{890. DOI: 10.1016/j.ajhg.2013.10.004.

39. Gehrke S, Brueckner B, Schepky A, et al. (2013). Epigenetic regulation of depot-specific gene expression in adipose tissue. PLoS One 8: e82516. DOI: 10.1371/journal.pone.0082516.

40. Egger G, Liang G, Aparicio A, et al. (2004). Epigenetics in human disease and prospects for epigenetic therapy. Nature 429: 457-463 DOI: 10.1038/nature02625.

41. Russell, PJ. (2010). Genetics: A Molecular Approach, 3rd ed.; Pearson Education, San Francisco, USA.

42. Erkmann J, Parisis N. (2011). Histone Modification Research Methods. Mater Methods 1:92. DOI//dx.doi.org/10.13070/mm.en.1.92

43. Villeneuve L M, Natarajan R. (2010). The role of epigenetics in the pathology of diabetic complications. Am J Physiol Renal Physiol 299: 14-25. DOI: 10.1152/ajprenal.00200.2010.

44. Kupczyk M, Kuna P. (2014). MicroRNAs, new biomarkers of respiratory tract diseases Pneumonol Alergol Pol 82:183\{190.

45. Kaspi H, Pasvolsky R, Hornstein E, et al. (2014) Could microRNAs contribute to the maintenance of cell identity? Trends Endocrinol Metab 25:285\{292. Doi: $10.3390 /$ genes 5041018

46. Ruiz M A, Chakrabarti S. (2013). MicroRNAs: the underlying mediators of pathogenetic processes in vascular complications of diabetes. Can J Diabetes 37:339\{344. DOI: 10.1016/j.jcjd.2013.07.003.
47. Kameswaran V, Bramswig NC, McKenna LB, et al. (2014). Epigenetic regulation of the DLK1-MEG3 microRNA cluster in human type 2 diabetic islets. Cell Metab 19:135\{145. DOI: 10.1016/j.cmet.2013.10.016

48. Poy M N, Eliasson L, Krutzfeldt J, et al. (2004). A pancreatic isletspecific microRNA regulated insulin secretion. Nature 432:226-230. DOI:10.1038/nature03076

49. Martínez J A, Milagro F I, Claycombe $\mathrm{K}$ J, et al. (2014). Epigenetics in adipose tissue, obesity, weight loss, and diabetes. Adv Nutr 5:71\{81. DOI: 10.3945/an.113.004705

50. Sivitz W. (2010). Mltochondrial Dysfunction in Obesity and Diabetes. US Endocrinology, 6 (1): 20-27 DOI: http://doi.org/10.17925/USE.2010.06.1.20.

51. Rönn T, Poulsen $P$, Hansson $O$, et al. (2008). Age influences DNA methylation and gene expression of COX7A1 in human skeletal muscle. Diabetologia 51:1159\{1168. DOI: 10.1007/s00125-008-1018-8.

52. Ling C, Poulsen P, Simonsson S, et al. (2007). Genetic and epigenetic factors are associated with expression of respiratory chain component NDUFB6 in human skeletal muscle. J Clin Invest 117: 3427\{3435. DOI: 10.1172/JCI30938.

53. Caro JF, Triester S, Patel VK, et al. (1995). Liver glucokinase: decreased activity in patients with type II diabetes. Horm Metab Res 27:19\{22. DOI: 10.1055/s-2007979899

54. Jiang MH, Fei J, Lan MS, et al. (2008). Hypermethylation of hepatic Gck promoter in ageing rats contributes to diabetogenic potential. Diabetologia 51:1525\{1533. DOI 10.1007/s00125-008-1034-8

55. 55. Grazioli E, Dimauro I, Mercatelli N, et al. (2017). Physical activity in the prevention of human diseases: role of epigenetic modifications. BIC Genomics 18 (Suppl 8): 802. Doi:10.1186/s12864-017-4193-5

56. Imam U M, Ismail M. (2017). The Impact of Traditional Food and Lifestyle Behavior on Epigenetic Burden of Chronic Disease. Global Challenge 1: 1700043. DOI: https://doi.org/10.1002/gch2.201700043

57. Knight JA. (2012). Physical inactivity: associated diseases and disorders. Ann Clin Lab Sci. 42:320\{337.

58. Warren TY, Barry V, Hooker SP, Sui X, Church TS, Blair SN. (2010). Sedentary behaviors increase risk of cardiovascular disease mortality in men. Med Sci Sports Exerc 42: 879\{885 Doi: 10.1249/MSS.0b013e3181c3aa7e.

59. Eriksson KF, Lindgärde F. (1996). Poor physical fitness, and impaired early insulin response but late hyperinsulinaemia, as predictors of NIDDM in middleaged Swedish men. Diabetologia 39:573 579.

60. O'Keefe JH, Vogel R, Lavie CJ, Cordain LC. (2011). Exercise like a huntergatherer: a prescription for organic physical fitness. Prog. Cardiovasc Dis 53:471. DOI:10.1016/j.pcad.2011.03.009

61. Alegría-Torres JA, Baccarelli A, Bollati V. (2011). Epigenetics and lifestyle. Epigenomics 3 (3):267-77. Doi: 10.2217/epi.11.22

62. Woelfel JR, Dudley-Javoroski S, Shields RK. (2018). Precision Physical Therapy: Exercise, the Epigenome, and the Heritability of Environmentally Modified Traits. Phys Ther 98 (11): 946\{952. https://doi.org/10.1093/ptj/pzy092

63. Scientific American. Methylating Your Muscle DNA. Available Online at https://blogs.scientificamerican.com/scicurious-brain/methylating-yourmuscle-dna/. (Accessed Jan 4 2019).

64. Ronn T, Volkov P, DavgardhC, et al. (2013). A six months exercise intervention influences the genome-wide DNA methylation pattern in human adipose tissue. PLOS Genetics 9:1- 16. DOI: 10.1371/journal.pgen.1003572.

65. Nitert M D, Dayeh T, Volkov, P, et al. (2012). Impact of an exercise intervention on DNA methylation in skeletal muscle from first-degree relatives of patients with type 2 diabetes. Diabetes 61:3322\{3332. DOI: 10.2337/db11-1653.

66. Karolinska Institute. Diabetes, obesity and exercise in skeletal muscle: effects on gene expression and DNA methylation. Available Online at https://openarchive.ki.se/xmlui/handle/10616/45248 (Accessed Jan 3 2019).

67. Neufer PD, Dohm GL. (1993). Exercise induces a transient increase in transcription of the GLUT-4 gene in skeletal muscle. Am J Physiol 265: C1597\{C1603. DOI:10.1152/ajpcell.1993.265.6.C1597

68. McGee SL, Hargreaves M. (2006). Exercise and skeletal muscle glucose transporter 4 expression: molecular mechanisms. Clin Exp Pharmacol Physiol 33:395\{399. DOI: 10.1111/j.1440-1681.2006.04362.x.

69. McGee S L, van Denderen BJ, Howlett KF, et al. (2008). AMP-activated protein kinase regulates GLUT4 transcription by phosphorylating histone deacetylase Diabetes 57: $860\{867$. DOI:10.2337/db07-0843

70. Smith J A, Kohn T A, Chetty A K, et al. (2008). CaMK activation during exercise is required for histone hyperacetylation and MEF2A binding at the MEF2 site on the Glut4 gene. Am J Physiol Endocrinol Metab 295: E698\{ E704. DOI: 10.1152/ajpendo.00747.2007.

71. Parikh $\mathrm{H}$, Nilsson $\mathrm{E}$, Ling $\mathrm{C}$, et al. (2008). Molecular correlates for maximal oxygen uptake and type 1 fibers. Am J Physiol Endocrinol Metab 294: E1152\{ E1159A. DOI: 10.1152/ajpendo.90255.2008

72. Learn Genetics. Nutrition and the Epigenome. Available Online at http://learn.genetics.utah.edu/content/epigenetics/nutrition/(Accessed Jan 2 2019).

73. Bach A, Aris A, Guasch I. (2017). Consequences of supplying methyl donors during pregnancy on the methylome of the offspring from lactating and non-lactating dairy cattle. PLOS One 12 (12): e0189581. https://doi.org/10.1371/journal.pone.0189581

74. O'Neill RJ, Vrana PB, Rosenfeld CS. (2014). Maternal methyl supplemented diets and effects on offspring health. Front Genet 5:289. Doi:10.3389/fgene.2014.00289 
75. Pembrey ME. (2002). Time to take epigenetic inheritance seriously. Eur J Hum Genet 10:M669-671. Doi:10.1038/sj.ejhg.5200901

76. Vaughn AC, Cooper EM, DiLorenzo PM, et al. (2017). Energy-dense diet triggers changes in gut microbiota, reorganization of gut-brain vagal communication and increases body fat accumulation. Acta Neurobiol Exp (Wars) 77 (1):18-30.

77. Masuyama H, Mitsui T, Eguchi T, et al. (2016). The effects of paternal high-fat diet exposure on offspring metabolism with epigenetic changes in the mouse adiponectin and leptin gene promoters. Am J of Physiol 311 (1): E236-E245 https://doi.org/10.1152/ajpendo.00095.2016

78. Soubry A, Murphy SK, Wang F, et al. (2013). Newborns of obese parents have altered DNA methylation patterns at imprinted genes. Int J Obes (Lond) 39 (4):6507. Doi: $10.1038 / i j o .2013 .193$

79. Soubry A, Guo L, Huang Z, et al. (2016). Obesity-related DNA methylation at imprinted genes in human sperm: Results from the TIEGER study. Clin Epigenetics 8:51. Doi:10.1186/s13148-016-0217-2

80. Keleher MR, Zaidi R, Shah S, et al. (2018). Maternal high-fat diet associated with altered gene expression, DNA methylation, and obesity risk in mouse offspring. PLoS One 13 (2): e0192606. https://doi.org/10.1371/journal.pone.0192606

81. Sullivan EL, Smith MS, Grove KL. (2011). Perinatal Exposure to High-Fat Diet Programs Energy Balance, Metabolism and Behavior in Adulthood. Neuroendocrinology 93:1-8 https://doi.org/10.1159/000322038.

82. Khan IY, Dekou V, Douglas G, et al. (2005). A high-fat diet during rat pregnancy or suckling induces cardiovascular dysfunction in adult offspring. Am J Physio Regul Integr Comp Physiol 288: R127\{R133. DOI:10.1152/ajpregu.00354.2004

83. Sun B, Purcell RH, Terrillion CE, Yan J, Moran TH, Tamashiro KL. (2012). Maternal high- fat diet during gestation or suckling differentially affects offspring leptin sensitivity and obesity. Diabetes 61 (11): 2833-41. Doi: 10.2337/db11-0957.

84. Godfrey KM, Sheppard A, Gluckman PD, Lillycrop KA, et al. (2011). Epigenetic gene promoter methylation at birth is associated with child's later adiposity. Diabetes 60 (5): 1528-34. Doi: 10.2337/db10-0979.

85. Relton CL, Groom A, St Pourcain B, et al. (2012). DNA methylation patterns in cord blood DNA and body size in childhood. PLoS One 7:e31821. Doi: 10.1371/journal.pone.0031821.

86. Sahoo K, Sahoo B, Choudhury AK, Sofi NY, Kumar R, Bhadoria AS. (2015). Childhood obesity: causes and consequences. J Family Med Prim Care 4 (2): 187-92. Doi: 10.4103/2249-4863.154628

87. Anderson OS, Sant KE, Dolinoy DC. (2012). Nutrition and epigenetics: an interplay of dietary methyl donors, one-carbon metabolism and DNA methylation. $J$ Nutr Biochem 23 (8):853-9. Doi: 10.1016/j.jnutbio.2012.03.003.

88. Sinclair KD, Allegrucci C, Singh R, et al. (2007). DNA methylation, insulin resistance, and blood pressure in offspring determined by maternal periconceptional B vitamin and methionine status. Proc Natl Acad Sci U S A 104 (49): 19351-6. DOI: 10.1073/pnas.0707258104

89. Della Pepa G, Vetrani C, Vitale M, Riccardi G. (2018). Wholegrain Intake and Risk of Type 2 Diabetes: Evidence from Epidemiological and Intervention Studies. Nutrients 10 (9): 1288. Doi:10.3390/nu10091288

90. Sahyoun NR, Jacques PF, Zhang XL, Juan W, McKeown NM. (2006). Whole-grain intake is inversely associated with the metabolic syndrome and mortality in older adults. AJCN 83 (1): 124\{31, https://doi.org/10.1093/ajcn/83.1.124.

91. Aune $D$, Norat $T$, Romundstad $P$, Vatten LJ. (2013). Whole grain and refined grain consumption and the risk of type 2 diabetes: a systematic review and doseresponse meta- analysis of cohort studies. Eur J Epidemiol 28 (11): 845-58. Doi: 10.1007/s10654-013-9852-5.

92. Bruntrup M. (2006). The rice market in Senegal. Agric Rur Dev 13: 1-23.

93. Imam MU, Ismail M, Ooi DJ, Sarega N, Ishaka A. (2015). Increased risk of insulin resistance in rat offsprings exposed prenatally to white rice. Mol. Nutr. Food Res 59:180. DOI:10.1002/mnfr.201400396

94. Chen PY, Ganguly A, Rubbi L, et al. (2013). Intrauterine calorie restriction affects placental DNA methylation and gene expression. Physiol Genomics 45 (14):56576. Doi: 10.1152/physiolgenomics.00034.2013.

95. Callaway E. (2014). Starvation in pregnant mice marks offspring DNA. Available Online at Doi:10.1038/nature.2014.15534

96. Tobi EW, Lumey LH, Talens RP, et al. (2009). DNA methylation differences after exposure to prenatal famine are common and timing- and sex-specific. Hum Mol Genet 18:4046\{ 4053. Doi: 10.1093/hmg/ddp353.

97. Knopik VS, Maccani MA, Francazio S, McGeary JE. (2012). The epigenetics of maternal cigarette smoking during pregnancy and effects on child development. Dev Psychopathol, 24(4):1377-90. Doi: 10.1017/S0954579412000776

98. Besingi W1, Johansson A. (2014). Smoke-related DNA methylation changes in the etiology of human disease. Hum Mol Genet 23 (9): 2290-7. Doi: $10.1093 / \mathrm{hmg} / \mathrm{ddt} 621$

99. Joehanes R, Just AC, Marioni RE, et al. (2016). Epigenetic Signatures of Cigarette Smoking. Circ Cardiovasc Genet 9 (5):436-447. DOI:10.1161/CIRCGENETICS.116.001506

100. Einarson A, Riordan S. (2009). Smoking in pregnancy and lactation: a review of risks and cessation strategies. Eur J Clin Pharmacol 65 (4):325\{330. Doi: 10.1007/s00228-008-0609-0

101. Wilhelm-Benartzi CS, Houseman EA, Maccani MA, et al. (2012). In Utero Exposures, Infant Growth, and DNA Methylation of Repetitive Element and Developmentally Related Genes Environ Health Persp. 120 (2): 296-302 Doi: 10.1289/ehp.1103927
102. Time. Epigenetics, DNA: How You Can Change Your Genes, Destiny. Available Online at http://www.time.com/time/printout/0,8816,1952313,00.html (Accessed Jan 4 2019)

103. Vuolo M, Staff J. (2013). Parent and Child Cigarette Use: A Longitudinal, Multigenerational Study. Pediatrics 132 (3): e568\{e577. Doi: 10.1542/peds.2013-0067

104. Ungerer M, Knezovich J, Ramsay M. (2013). In utero alcohol exposure, epigenetic changes, and their consequences. Alcohol Res 35 (1): 37-46.

105. Puumala SE, Hoyme HE. (2015). Epigenetics in Pediatrics. Pediatr Rev 36 (1): 1-50 http://pedsinreview.aappublications.org/

106. Schuckit MA, Tipp JE, Smith TL, Wiesbeck GA, Kalmijn J. (1997b). The relationship betweenSelf-Rating of the Effects of Alcohol and alcohol challenge results in ninety-eight young men. $J$ Stud Alcohol 58: 397\{404

107. Skinner MK, Manikkam M, Tracey R, Guerrero-Bosagna C, Haque M, Nilsson EE. (2013). Ancestral dichlorodiphenyltrichloroethane (DDT) exposure promotes epigenetic transgenerational inheritance of obesity. BMC Med 23: 11:228. Doi: 10.1186/1741-7015-11-228

108. Alonso-Magdalena P, Rivera FJ, Guerrero-Bosagna C. (2016). Bisphenol-A and metabolic diseases: epigenetic, developmental and transgenerational basis. Environ Epigenet 2 (3): dvw022. Doi:10.1093/eep/dvw022

109. Anway MD, Leathers C, Skinner MK. (2006). Endocrine disruptor vinclozolin induced epigenetic transgenerational adult-onset disease. Endocrinology 147 (12):5515-23. https://doi.org/10.1210/en.2006-0640

110. Kaminskas E, Farrell AT, Wang Y-C, Sridhara R, Pazdur R. (2005). FDA drug approval summary: azacitidine (5-azacytidine, VidazaTM) for injectable suspension. Oncologist 10:176\{182. https://doi.org/10.1634/theoncologist.10-3-176

111. García-Calzón S, Perfilyev A, Männistö V, et al. (2017). Diabetes medication associates with DNA methylation of metformin transporter genes in the human liver. Clin Epigenetics 9:102. doi:10.1186/s13148-017-0400-0

112. El-Hadidy WF, Mohamedb AR, Mannaac HF. (2015). Possible protective effect of procainamide as an epigenetic modifying agent in experimentally induced type 2 diabetes mellitus in rats. Alexandria $J$ Med 51 (1): 65-71 http://dx.doi.org/10.1016/j.ajme.2014.02.004

113. Balasubramanyam K, Altaf M, Varier RA, et al. (2004). Polyisoprenylated benzophenone, garcinol, a natural histone acetyltransferase inhibitor, represses chromatin transcription and alters global gene expression. $J$ Biol Chem 279:33716-26 https://doi.org/10.1074/jbc.M402839200

114. Kadiyala CS, Zheng L, Du Y, et al. (2012). Acetylation of retinal histones in diabetes increases inflammatory proteins: effects of minocycline and manipulation of histone acetyltransferase (HAT) and histone deacetylase (HDAC). J Biol Chem 287:25869- 80. https://doi.org/10.1074/jbc.M112.375204

115. Tedong L, Madiraju P, Martineau LC, et al. (2010). Hydro-ethanolic extract of cashew tree (Anacardium occidentale) nut and its principal compound, anacardic acid, stimulate glucose uptake in $\mathrm{C2C12}$ muscle cells. Mol Nutr Food Res 54:1753-62. https://doi.org/10.1002/mnfr.201000045

116. Zhang DW, Fu M, Gao SH, Liu JL. (2013). Curcumin and diabetes: a systematic review. Evid Based Complement Alternat Med Article ID 636053. https://doi.org/10.1155/2013/636053

117. Wickenberg J, Ingemansson SL, Hlebowicz J. (2010). Effects of Curcuma longa (turmeric) on postprandial plasma glucose and insulin in healthy subjects. Nutr J 9:43 https://doi.org/10.1186/1475-2891-9-43

118. Bassett SA, Barnett MPG. (2014). The Role of Dietary Histone Deacetylases (HDACs) Inhibitors in Health and Disease. Nutrients 6:4273-4301. doi: $10.3390 / n u 6104273$

119. Marks PA. (2010). Histone deacetylase inhibitors: a chemical genetics approach to understanding cellular functions. Biochim Biophys Acta 1799: 717\{725. DOI:10.1016/j.bbagrm.2010.05.008

120. Broderick JA, Zamore PD. (2011). MicroRNA therapeutics. Gene Ther 18:1104-10. https://doi.org/10.1038/gt.2011.50

121. Kolfschoten IG, Roggli E, Nesca V, Regazzi R. (2009). Role and therapeutic potential of microRNAs in diabetes. Diabetes Obes Metab 11 (Suppl 4) :118-29. https://doi.org/10.1111/j.1463-1326.2009.01118.x

122. El Ouaamari A, Baroukh N, Martens GA, et al. (2008). miR-375 targets 3- phosphoinositide-dependent protein kinase-1 and regulates glucoseinduced biological responses in pancreatic -cells. Diabetes 57:2708-17. https://doi.org/10.2337/db07-1614

123. Trajkovski M, Hausser J, Soutschek J, et al. (2011). MicroRNAs 103 and 107 regulate insulin sensitivity. Nature 474:649-53. https://doi.org/10.1038/nature10112

124. Lundh M, Christensen DP, Damgaard NM, et al. (2012). Histone deacetylases 1 and 3 but not 2 mediate cytokine-induced beta cell apoptosis in INS-1 cells and dispersed primary islets from rats and are differentially regulated in the islets of type 1 diabetic children. Diabetologia 55:2421-2431. DOI:10.1007/s00125-0122615-0

125. Yamato E. (2018). High dose of histone deacetylase inhibitors affects insulin secretory mechanism of pancreatic beta cell line. Endocr Regul 52 (1) $21\{26$. doi:10.2478/enr-2018-0004.

126. Christensen DP, Dahllof M, Lundh M, et al. (2011). Histone deacetylase (HDAC) inhibition as a novel treatment for diabetes mellitus. Mol Med 17:378\{390. DOI:10.2119/molmed.2011.00021

127. Tiernan AR, Champion JA, Sambanis A. (2015). Trichostatin A affects the secretion pathways of beta and intestinal endocrine cells. Exp Cell Res 330: 212\{21. doi: 10.1016/j.yexcr.2014.09.031 
128. Khan S, Jena GB. (2014). Protective role of sodium butyrate, a HDAC inhibitor on beta- cell proliferation, function and glucose homeostasis through modulation of p38/ERK MAPK and apoptotic pathways: study in juvenile diabetic rat. Chem Biol Interact 213: 1- 12. DOI:10.1016/j.cbi.2014.02.001

129. Mao Y, Mohan R, Zhang S, Tang X. (2013). MicroRNAs as Pharmacological Targets in Diabetes. Pharmacol Res 75: 37 \{47. doi: 10.1016/j.phrs.2013.06.005

130. Vester B, Wengel J. (2004). LNA (locked nucleic acid): high-affinity targeting of complementary RNA and DNA. Biochemistry 43:13233\{41. DOI:10.1021/bi0485732

131. Orom UA, Kauppinen S, Lund AH. (2006). LNA-modified oligonucleotides mediate specific inhibition of microRNA function. Gene 372:137\{41. DOI:10.1016/j.gene.2005.12.031
132. Putta S, Lanting L, Sun G, Lawson G, Kato M, Natarajan R. (2012). Inhibiting microRNA- 192 ameliorates renal fibrosis in diabetic nephropathy. J Am Soc Nephro 23:458-69. doi: 10.1681/ASN.2011050485

133. Elmen J, Lindow M, Schutz S, et al. (2008). LNA-mediated microRNA silencing in non- human primates. Nature 452:896-9. doi: 10.1038/nature06783

134. SeongHo Jo, Junqin Chen, Guanlan Xu, et al. (2018). Mir-204 Controls GlucagonLike Peptide 1 Receptor Expression and Agonist Function. Diabetes 67 (2): 256264. DOI: $10.2337 / \mathrm{db} 17-0506$ 